\section{A descriptive study of associated factors with HIV/AIDS among antiretroviral users of Eastern Nepal}

Khanal VK, ${ }^{*}$ Rayamajhi RB, ${ }^{1}$ Neupane $B,{ }^{2}$ Kafle SU, ${ }^{3}$ Thapa B, ${ }^{4}$ Karki P,1 Paudel IS, ${ }^{1}$ Jha N1

1School of Public Health and Community Medicine, B. P. Koirala Institute of Health Sciences, Dharan, Nepal, ${ }^{2}$ College of Medical Sciences, Bharatpur, Chitwan, ${ }^{3}$ Department of Pathology, B. P. Koirala Institute of Health Sciences, Dharan, Nepal, ${ }^{4}$ Nobel Medical College, Biratnagar, Nepal

*Correspondence to: Dr. Vijay Kumar Khanal, School of Public Health and Community Medicine, B.P. Koirala Institute of Health Sciences, Dharan, Sunsari, Nepal. email: vijaykhanal75@gmail.com, Te. No.: (+977) 9845133117

\begin{abstract}
INTRODUCTION: In Nepal, the firstcase of Human Immunodeficiency Virus (HIV) was reported in 1988 , since then the epidemic is driven by sexual transmission and intravenous drug use. The aim of this research is to study various associated factors with HIV/AIDS patients.
\end{abstract}

MATERIALS AND METHODS: A cross-sectional study was carried out from May 2009 - April 2010 at three Anti-retroviral treatment centers (B.P.K.I.H.S, Dharan, Koshi Zonal Hospital, Biratnagar and Mechi Zonal Hospital, Bhadrapur). A purposive sampling technique was applied to include all 234 seropositive patients who were under medication from these centers.

RESULTS: Males represented $71 \%$ of the patients. More than $75 \%$ of the patients fell in the age group of 20-39 years. $35.9 \%$ of them had visited commercial sexual workers and similar proportion of them had shared needles during intravenous drug use.

CONCLUSIONS: Unsafe high risk behavior with commercial sexual worker and needle sharing habit were found to be the associated with HIV/AIDS patients.

KEY WORDS: HIV/AIDS, Commercial sexual worker, Man sex with man

Article submitted 20 August. Reviewed 29 August. Author correction 1 September. Final version accepted 10 September 2013. 


\section{INTRODUCTION}

AIDS was first recognized in the United States in the summer of 1981 by Center for Disease Control and Prevention (CDC) for the unexplained occurrence of Pneumocystis jiroveci (formerly $P$. carinii) pneumonia in five previously healthy homosexual men in Los Angeles and of Kaposi's sarcoma (KS) with or without $P$. jiroveci pneumonia in 26previously healthy homosexual men in New York and Los Angeles. Later the disease became recognized in male and female injection drug users and soon thereafter in recipients of blood transfusion and in hemophiliacs. ${ }^{1}$ In Nepal, the first case was reported in 1988; since then more than fifty thousand HIV positive cases had been reported to the National Centre for AIDS and STD control as of November 2012; with a national prevalence of 0.3 . The largest number of HIV positive cases in the last 18 months was reported among 30-39 and 2429 years old and $42 \%$ of HIV cases reported was among men and women aged 30to 39 years old while 22 percent were among young men and women aged24 to 29 years old. National level cumulative data shows more than 101,578 cases of AIDS and more than thousand deaths reported. The sex ratio among HIV positive cases is 2.9:1.2 The epidemic in Nepal is driven by sexual transmission and injecting drug use. There are numerous social, economical and cultural factors that drive the injecting and sexual behaviors among various mostat-risk groups.

The infection rate of HIV/AIDS in Nepal among the adult population is estimated to be below the 1 percent threshold which is considered "generalized and severe". However, the prevalence rate masks a concentrated epidemic among at-risk populations such as female sex workers, injecting drug users, men who have sex with men and migrants. Cultural factors have also been shown to play a significant role in the spread of HIV and AIDS in Nepal. ${ }^{8}$ Various factors associated with HIV infection are unsafe sex and drug injection practices, civil conflict, internal and external mobility, and limited adequate health care delivery multiply the difficulties of addressing HIV/AIDS. Moreover, existing care and support services are already overwhelmed as increasing numbers of HIVinfected individuals become sick with AIDS. ${ }^{9}$ The aim of this research is to study various associated factors with HIV/AIDS patients in Nepal.

\section{MATERIALS AND METHODS}

This was a cross sectional study with purposive sampling from May 2009 - April 2010. The study was undertaken in three ARV centre in the eastern Nepal (Tropical ward, BPKIHS Dharan, Koshi Zonal Hospital and Mechi Zonal Hospital). All patients who were under medication from these centers were included in the study. Interview was conducted by face to face interview using pre-tested semistructured questionnaire. Questionnaires were pretested in BPKIHS for its validity and reliability. Written informed understood consent was taken prior to the study and confidentiality was maintained with the information gathered. Questionnaire included information on socioeconomic and demographic characteristics and epidemiological factors associated with HIV/AIDS. Ethical clearance was taken from the institutional ethical review board of B. P. Koirala Institute of Health Sciences. The variables were coded and entered in Excel software. The statistical analysis was done by SPSS 11.5 version to calculate frequency, percentage and mean.

\section{RESULTS}

Among the participants, the mean age was calculated to be 33 years. It was also found that $70.9 \%$ of them were male and more than half of them were in the age group of 30-39 years. It was also reported that $75.5 \%$ of them were married and $32.1 \%$ of them had not undergone any formal education. It was also observed that about one third $(31.2 \%)$ of them were unemployed (Table 1 ).

Among the participants, more than one third of them had high risk behavior with the commercial sex worker $(35.9 \%)$ and approximately one third were intravenous drug users (32.9\%) (Table 2).

It was also observed that more than one third of them believed heterosexual (35.5\%) and needle sharing habit among friends (35.9\%) as the cause of HIV transmission to them. Very few reported blood transfusion $(2.1 \%)$ and mother to child transmission $(1.3 \%)$ as the cause behind the infection (Table 3 ).

\section{DISCUSSION}

HIV infection has maintained to be a global threat to mankind far more extensive than it was predicted a decade ago. The pace of the epidemic is accelerating all over the word and especially south Asia and subSaharan region. ${ }^{3}$ This study showed that most of the respondents among the HIV/AIDS patients were male $(71 \%)$ and the male to female ratio was reported to be 2.4 to 1.Similar study done at Aligarh by Zaheer MS et al. reported mean age of patients to 
Table 1. Socio-demographic characteristics of respondents $(n=234)$

\begin{tabular}{llcc}
\hline Characteristics & & Frequency & Percentage \\
\hline Sex & Male & 166 & 70.9 \\
Age Group (Years) & Female & 68 & 29.1 \\
& $0-19$ & 6 & 2.6 \\
& $20-29$ & 60 & 25.6 \\
Marital status & $30-39$ & 132 & 56.4 \\
& $>40$ & 36 & 15.4 \\
& Married & 177 & 75.5 \\
Education level & Unmarried & 36 & 15.5 \\
& Widow/ Widower/ Separated & 21 & 9.0 \\
Occupation & Informal education & 75 & 32.1 \\
& Primary education & 114 & 48.7 \\
& Secondary and above & 45 & 19.2 \\
& Unemployed & 73 & 31.2 \\
& House wife & 53 & 22.6 \\
& Skilled/unskilled labor & 64 & 27.4 \\
\hline
\end{tabular}

Table 2. Distribution of high risk behavior among the respondents $(n=234)$

\begin{tabular}{lcc}
\hline Characteristics & Frequency & Percentage \\
\hline Risk behavior & 77 & 32.9 \\
Intravenous Drug Use & 84 & 35.9 \\
Commercial Sex Workers & 2 & 0.9 \\
Man Sex with Man & 71 & 30.3 \\
No any significant risk behavior & & \\
\hline
\end{tabular}

Table 3. Mode of transmission for HIV infections among the respondents $(n=234)$

\begin{tabular}{lcc}
\hline Characteristics & Frequency & Percentage \\
\hline Mode of transmission & & 35.5 \\
Heterosexual & 83 & 35.9 \\
Needle sharing & 84 & 23.1 \\
From husband & 54 & 1.3 \\
Mother to child & 3 & 2.1 \\
Blood transfusion & 5 & 2.1 \\
Others & 5 & \\
\hline
\end{tabular}

be 29.6 years and the male to female ratio was $2.4: 1$ which is highly consistent with our study. ${ }^{7}$ This could be due to the risk behavior male counterparts adopt in a patriarchal society. This finding was slightly higher than a similar study done by Dhungana GP et.al in which $66 \%$ males were HIV infected but consistent with the finding by Das which showed $74.3 \%$ of the males were infected. ${ }^{4,5}$ Our study found that $35.5 \%$ of the patients believed their heterosexual relationship as a mode of transmission of HIV and the other $35.9 \%$ mentioned their needle sharing habit during intravenous drug use as the cause behind the transmission. Worldwide heterosexual transmission is reported to be the most common mode of transmission. In a similar study by Das et al of Manipal teaching hospital, Pokhara $61 \%$ of the patients were found to have transmitted HIV infection through unsafe hetero sexual relationship and the other $22 \%$ transmitted by sharing needles among their intravenous drug user friends. ${ }^{5}$ Similarly,Myoungdon $\mathrm{Oh}$ et al from Korea reported that $62 \%$ of his patients transmitted the infection secondary to unsafe heterosexual contacts and this finding is similar to our study. ${ }^{6}$ Similarly another study by Zaheer et al of Aligarh also reported that 56.3\% of the patients in his research were infected through sexual contact. ${ }^{7}$

A large proportion of people who have HIV infection but aren't under medication aren't included in this study which is one of the main limitation of this study. Similarly, retrospective inquiry of the mode of HIV infection transmission 
is one of the other limitations.

\section{CONCLUSIONS}

Our study concluded thatyoung males are more vulnerable to get HIV infection transmitted due to their high risk taking tendencies as compared to females. Similarly unsafe sexual contact with commercial sex workers, heterosexual contact and needle sharing habit were found to be associated with transmission of HIV infection. Thus, this study advocated the high chances of HIV transmission among high risk behavior people.

\section{ACKNOWLEDGEMENTS}

Our sincere acknowledgement to Mrs. Shobha Poudel, Dr. Samyog Uprety, Dr. Shyam Sundar Budhathoki and the nursing staffs of Tropical ward of B. P. K. I. H. S, Koshi Zonal Hospital, Biratnagar and Mechi Zonal Hospital, Bhradapur. We are also thankful to B. P. Koirala Institute of Health Sciences for the valuable time.

CONFLICT OF INTEREST: None

FINANCIAL INTEREST: None

\section{REFERENCES}

1. Fauci A, Kasper D, Hauser S, Longo DL, Jameson JL, Locsalzo J. Principles of internal medicine, Harrison's 17th ed.

2. Nepal HIV Country report. UNGASS country report Nepal. 2012

3. AIDS epidemic update: December 2000.Geneva: UNAIDS/WHO, 2000. Publication UNAIDS/00.44EWHO/CDS/CSR/EDC/2000.

4. Dhungel BA, Dhungel KU, Easow JM, Singh YI. Opportunistic infection among HIV seropositive cases in Manipal Teaching Hospital, Pokhara, Nepal. Kathmandu Uni Med J 2008;6:335-339.

5. Das RN, Joshi HS, Biswas R. Opportunistic infection and clinic-epidemiological factors in HIV/AIDS cases seen in a tertiary care hospital in Nepal. African J Clin Exp Microbiol 2005;3:239-245.

6. oh Myoung-don, Park SW, Kim USK, et al. Spectrum of Opportunistic Infections and Malignancies in Patients with Human Immunodeficiency Virus Infection in South Korea. Clin Infect Dis 1999;29:1524-1528.

7. Zaheer MS, Rabbani MU, Ahmad Z, Khan T, Rewari BB. Clinical and Demographic Profile of Patients of AIDS in and around Aligarh. J Indian Acad Clin Med 2003;4:121126.

8. David B. 2003. Ensnared by AIDS: Cultural Contexts of HIV/AIDS in Nepal. Kathmandu, Nepal: Mandala Book Point.

9. Health Profile: Nepal. United States Agency for International Development (March 2008).
Citing this article

Khanal VK, Rayamajhi RB, Neupane B, et al. A descriptive study of associated factors with HIV/AIDS among antiretroviral users of Eastern Nepal. Int J Infect Microbiol 2013;2(3):95-98. 